\title{
The Relationship of Cellular Differentiation to Colonial Morphogenesis of the Blue-green Alga, Nostoc muscorum A
}

\author{
BY N. LAZAROFF* AND W. VISHNIAC \\ Department of Microbiology, Yale University, New Haven, Connecticut, U.S.A.
}

(Received 23 December 1963)

\begin{abstract}
SUMMARY
The morphogenesis of organized thalli in pure cultures of Nostoc muscorum a was found to be dependent upon the sequential differentiation of specialized cells and filaments. In a culture of $N$. muscorum previously kept in darkness, a brief exposure to light induced development during subsequent incubation in darkness, and resulted in the formation of simple unbranched thalli. Such structures are interpreted as being the product of a single complete turn of the developmental cycle. Continuous illumination produces ramified thalli (dendroid macrostructures) which bend toward the source of light. The various differentiated cell and filament stages of development are oriented within the dendroid thallus. The presence of glucose in culture media prolongs growth at the heterocystous filament stage. The consequent inability to form motile hormogonia leads to the growth of a thallus lacking an ordered macroscopic structure. The term lanose structure is applied to this form to describe its fleece-like appearance.

Hormogone development in cultures of Nostoc muscorum a appears to be sensitive to a metabolic product. In cultures containing glucose this product is formed rapidly, hence a lanose macrostructure results. In cultures containing sucrose, the breakdown of organized thalli and formation of a lanose macrostructure takes place only after prolonged incubation. It is suggested that the pattern of organization in other, more complex, cyanophycean colonies may arise similarly from a photoinduced sequence of cellular and filamentous development.
\end{abstract}

\section{INTRODUCTION}

It has long been recognized that some filamentous genera of the blue-green algae may be found in nature to display the form of organized macrocolonies (Bornet \& Thuret, 1880; Geitler, 1932). These colonies reflect the widespread occurrence of differentiated cells and filaments within the cyanophycean thallus. Many examples of ordered colonies may be cited among species of Gloeotrichia and Rivularia, in which the component filaments are radially arranged and display a base to apex polarity. The round colonies of these genera are composed of filaments whose terminal heterocysts are directed toward the centre of the colony while the tapered hair cells point away from the centre (Fremy, 1930; Fritsch, 1945; Von Zastrow, 1953). Less complex, but equally significant examples, may be found among other families. In

\footnotetext{
* Present address: Department of Biology, University of Southern California, Los Angeles, California, U.S.A.
} 
a planktonic bloom colonies of Anabaena circinalis exhibit a radially symmetrical arrangement of component filaments (see Fig. 1). Similarly, we may note the regular arrangement of filaments in 'punctiforme' colonies of many species of Nostoc (Geitler, 1932). Further indication that the cyanophycean thallus possesses a supra-filamentous organization may be seen in the phototropic behaviour of Tolypothrix colonies (Manten, 1948). The thallus of Tolypothrix is composed of filaments organized as erect tufts which act as integrated structures when bending toward a source of light.

In most cases, the filamentous blue-green algae which form ordered colonies in nature lack organized thallus structure when cultivated in the laboratory (G. R. Fitzgerald and J. McLachlan, personal communications). This has been true of many Nostocaceae, except for the report by Cannabaeus (1929) that Anabaena variabilis produced erect rod-like macrostructures (Säulchen) a few millimetres in height, when grown in laboratory culture. Our studies with pure cultures of the filamentous blue-green alga Nostoc muscorum A had shown that this organism possesses a photo-induced cycle of development at the cellular level of organization, as well as an organized colonial development (Lazaroff, 1955; Lazaroff, 1960). Therefore, it seemed of interest to examine the relationship of the developmental cycle to morphogenesis of thallus structure in the hope of understanding the factors responsible for colonial organization.

\section{METHODS}

The strain of Nostoc muscorum used for these studies has been previously designated $N$. muscorum A to identify it as the bacteria-free uni-algal stock first described by Allison et al. (1937). In our hands this strain has been repeatedly cloned by isolation of single hormogonia. In all cases these clones have shown the developmental cycle previously reported (Lazaroff \& Vishniac, 1961); this paper describes the culture media and general techniques of cultivation used in the work reported below.

Colonial structure was studied in thalli of Nostoc muscorum a grown in a variety of culture systems. These included stationary tube cultures, continuously agitated flasks, aerated submerged cultures with internal illumination, and a system by which the development of microcolonies in thin layers of agar could be continuously observed. The latter technique consisted of seeding cooled molten agar medium with a suspension of trichomes obtained by briefly grinding a culture in a Waring Blendor. Approximately $3 \mathrm{ml}$. of seeded agar was then pipetted into sterile inverted Carrel flasks and allowed to solidify. This resulted in a layer of seeded agar which adhered to the upper surface of the flask. The seeded flasks were incubated in darkness or light and developing colonies examined under high magnification.

Photomicrographs were made with a Leitz Ortholux microscope equipped with a Makam camera on Kodak Panatomic X or Agfa Hypan sheet film. Photographs of colonial development in culture tubes were made with the tubes immersed in water in a cuvette with optical sides. This device served to minimize distortion produced by the curved surfaces of the culture tubes. 


\section{RESULTS \\ Cell-filament morphology}

The growth of Nostoc muscorum a in vitro is accompanied by the regular formation of differentiated cells and filaments (Lazaroff, 1955). Some of these forms are reviewed in Pls. 1, 2 and 3 (Figs. 2-10).

Development at the filamentous level of organization involves several types of differentiation. One type is the formation of morphologically specialized cells. These include the cylindrical or barrel-shaped cells of hormogonia and their parent filaments, the large subspherical 'aseriate' cells, the heterocysts (terminal and intercalary), the spores and spore germlings. The morphological cell types also differ in their capacity to produce sheath material. The cells of motile hormogonia and the heterocysts do not possess sheaths. In contrast, the aseriate stage, which develops from hormogonia, displays a gelatinous membrane enclosing packets of cells. As the aseriate packets develop into long heterocystous filaments, the firm gelatinous membranes become loose slimy matrices (Pl. 1, fig. 4). The hormogonia escape from these slimy masses leaving heterocysts behind. The cells of hormogonia begin to form sheath material only after swarming has ceased and differentiation of the aseriate phase is about to begin.

The alternative development of sporogenous (instead of heterocystous) filaments from the aseriate stage (Lazaroff \& Vishniac, 1962) presents a different pattern of sheath formation. Each cell or spore of sporogenous filaments is individually ensheathed, as are the developing spore germlings. When the germlings swarm, a slimy sheath is left behind which retains the form of the cells which were enclosed (Pl. 2, fig. 5).

It was previously reported that the aseriate cells and their immediate progeny exhibit the ability to anastomose (Lazaroff \& Vishniac, 1962). This capacity, as well as the motility of hormogonia and spore germlings, represents an example of functional specialization within the nostocacean thallus. An additional specialized capacity at the filamentous level of organization may be observed in the ability of the motile forms of Nostoc to become oriented in remarkable patterns of swarming trichomes. These often appear as revolving spiral aggregations of individual gliding filaments (Pl. 2, fig. 6). Such formations are not caused by strain patterns in a solid substrate, since they occur in liquid cultures or in subsurface colonies as well as on the surface of solid media (Pl. 2, figs. 7, 8). Although the mechanism which controls the aggregation of motile trichomes is unknown, we may speculate on the significance of this specialized function. If the anastomosis of cells derived from the aseriate stage accomplishes the transfer of genetic material then the preliminary aggregation of hormogonia may be viewed as an important adjunct to this process. The hormogonia which serve to propagate thalli of the Nostocaceae may, by aggregation, bring in juxtaposition cells capable of transferring genetic material. Some evidence supporting this speculation has been found by continuous observation of the development of young thalli from spiral aggregates of hormogonia. It may be seen from Pl. 3, fig. 9, that ample opportunity occurs for the anastomosis of aseriate cells derived from different hormogonia. 


\section{Thallus morphogenesis}

Cultures of Nostoc muscorum a commonly occur in the form of an organized thallus whose structure reflects the sequential development of specialized filaments. This is shown by the comparison of illuminated cultures grown in media containing glucose with cultures grown in media containing sucrose. Although growth in the light initially exhibits all developmental stages regardless of whether the organism is grown under autotrophic or heterotrophic conditions, the presence of glucose exerts additional developmental effects. Superficially this effect is the inhibition of motile trichome formation. After an initial normal period of development, cultures which develop in the presence of glucose in the light exhibit a prolonged phase of growth as heterocystous filaments, with additional modification of the differentiated heterocysts ( $\mathrm{Pl}$. 3, fig. 10). This produces extremely long non-motile filaments with elongated or flask-shaped intercalary heterocysts. These filaments eventually break at an intercalary heterocyst, but breakage occurs between the heterocyst and only one of its adjacent cells. Consequently, filaments with terminal heterocysts are formed, instead of free heterocysts which arise in the absence of glucose. The filaments, so produced, are capable of an oscillatory motion and can form the aseriate phase of development. The cells of long filaments formed in glucose cultures usually contain round refractile inclusions commonly located at the point of attachment of adjacent cells. These structures are shown in Pl. 3, fig. 11.

The macroscopic appearance of mature cultures grown in presence of glucose clearly distinguishes them from cultures containing sucrose. Whereas light-grown cultures in inorganic media or in media containing sucrose, are at first crustose then form erect branching macrostructures, cultures grown in media containing glucose appear as a loose non-adherent mass of long filaments. The sucrose type of growth is termed dendroid, to describe its ramified tree-like macromorphology (Pl. 3, fig. 12), while the glucose type is designated as lanose in reference to its woolly appearance (Pl. 4, fig. 13). In basal media or in media containing sucrose, the appearance of tufts may be delayed for variable lengths of time. In such cases, the macromorphology is termed parenchymatous and consists of a sheet of filaments which adheres to the bottom and wall of the culture vessel (Pl. 3, fig. 12).

When tube cultures containing sucrose are incubated in darkness until the slowly growing cyanophyte is synchronized at its aseriate stage of development, exposure to light produces erect macrostructures during a subsequent dark incubation. Unlike the ramified macrostructures formed during continuous illumination, these are mostly unbranched (Pl. 4, fig. 14). Their formation depends, indirectly, upon the same photo-inductive process which triggers development at the cell-filament level of organization (Lazaroff \& Schiff, 1962). Photo-induction causes the sequential production of heterocystous filaments and hormogonia, which results in the ordered arrangement of elements within the dendroid thallus. The relationship of the elements of the developmental cycle to the structure of a dendroid thallus is shown in Fig. 1. The branching outer portions of the macrostructure consist of elongating filaments with intercalary heterocysts. These heterocystous filaments produce hormogonia from their basal portions. The hormogonia ascend to the tips of the branches (Pl. 4, figs. 15, 16) and form the aseriate stage which eventually produces new heterocystous filaments. The periodic formation of motile hormogonia is 


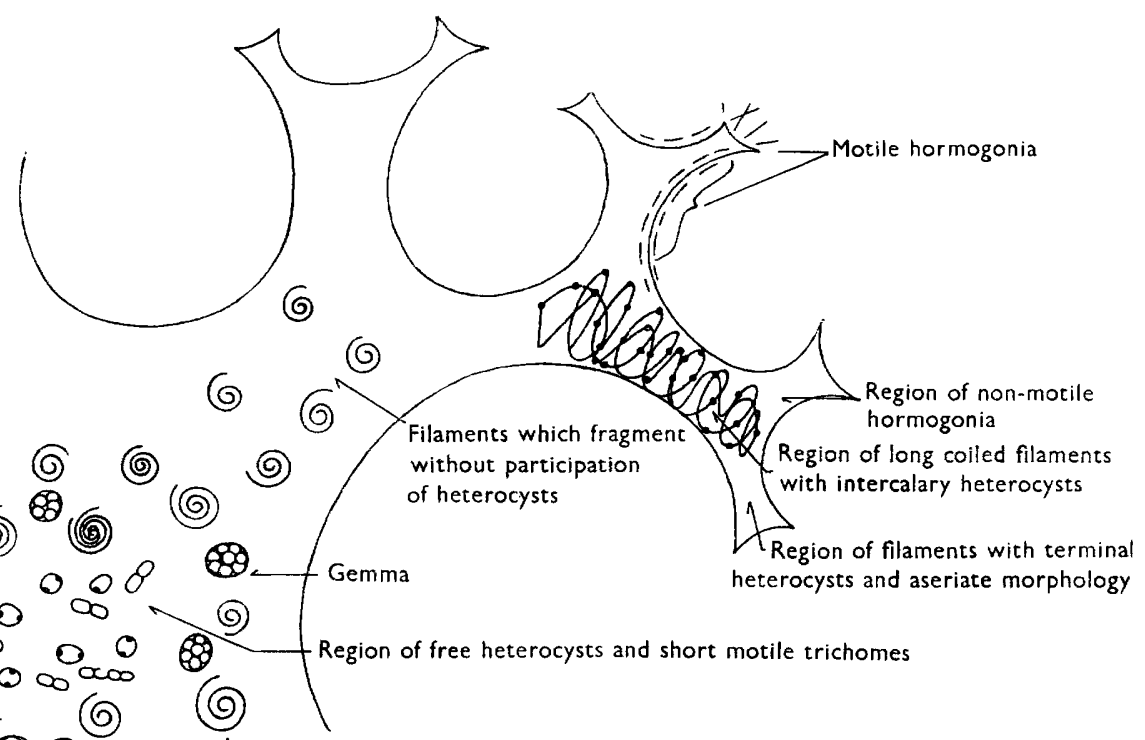

(19)

(a) $L_{\text {Spiral aggregate of motile trichomes }}$

Fig. 1. Anatomy of the dendroid macrostructure.

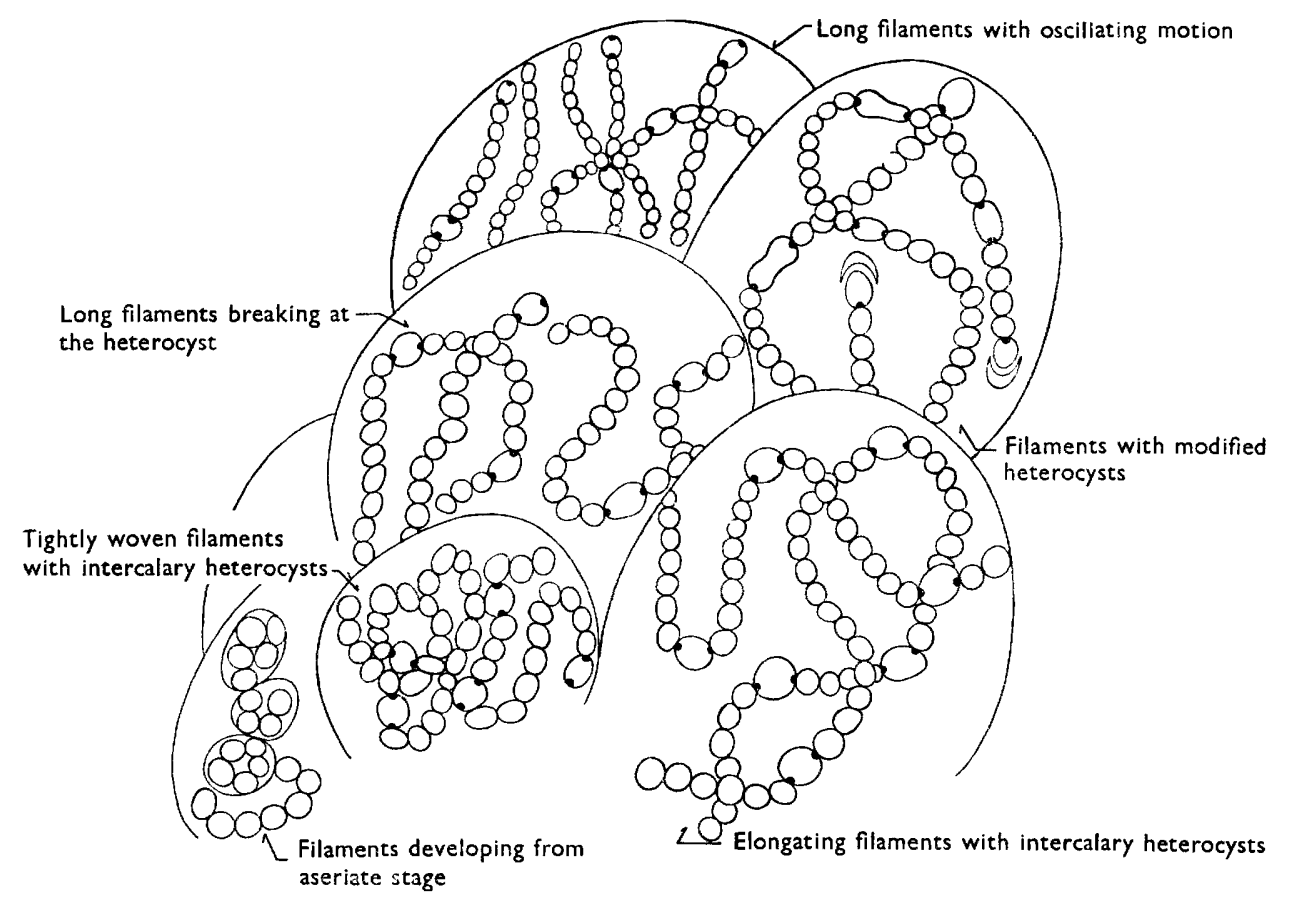

Fig. 2. Anatomy of the lanose macrostructure. 
related, in some unknown manner, to the dichotomous branching of the dendroid thallus. The simple unbranched erect macrostructures produced in darkness subsequent to a light exposure, result from a single complete cycle of filamentous development and its crop of swarming trichomes. The process of hormogone formation, movement and development result in a deposition of heterocysts in the older portion of the thallus. The central portion of the thallus also contains spiral aggregates of comparatively short motile trichomes, as well as multicellular spore-like structures (gemmae) which may develop from these spiral aggregates (Pl. 5, fig. 17).

Table 1. $p H$ value of cultures of Nostoc muscorum a after growth in the light or in darkness

Initially the culture solution was at pH 7.3. Basal medium I (Lazaroff \& Vishniac, 1961).

\section{Additions}

Sucrose, $1 \%$

Sucrose, $1 \%$

Sucrose, $0.5 \%$

Glucose, $1 \%$

Glucose, $1 \%$

Glucose, $2 \%$

Glucose + sucrose, $1 \%$ each

None

None

Sucrose, $1 \%$

Glucose, $1 \%$

$\begin{array}{cc}\text { Length of } & \text { Final } \\ \text { incubation } & \mathrm{pH} \\ \text { (days) } & \text { value }\end{array}$

Illumination

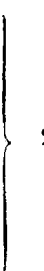

250 ft. c. $\left\{\begin{array}{l}33 \\ 70 \\ 70 \\ 33 \\ 70 \\ \text { Dark } \\ \text { Dark }\end{array}\right.$

$6 \cdot 9$

$5 \cdot 3$

$6 \cdot 3$

$5 \cdot 2$

$5 \cdot 3$

$5 \cdot 0$

$5 \cdot 1$

$6 \cdot 6$

$6 \cdot 2$

$7 \cdot 0$

$6 \cdot 7$

\section{Development}

Dark green dendroid

Dark green dendroid

Dark green dendroid

Green lanose

Bleached* lanose

Bleached lanose

Bleached lanose

Parenchymatous

Dendroid

Slight growth

Slight growth

* Loss of colour occurs in senescent cultures which have developed low $\mathrm{pH}$.

Table 2. Effect of buffering on macro-morphology of Nostoc muscorum $A$

Buffer, $0 \cdot 1 \mathrm{~m}$-tris buffer. Original $\mathrm{pH}$ value in tubes without buffer, $\mathrm{pH} 7 \cdot 2$; in tubes with buffer, $\mathrm{pH} 7 \cdot 4-7 \cdot 5$. Incubation for 20 days at light intensity of $150 \mathrm{ft}$. candles.

$\begin{array}{lccl} & \begin{array}{c}\text { Volume } \\ \text { of buffer } \\ \text { added } \\ \text { Medium }\end{array} & \begin{array}{c}\text { Final } \\ \text { pH }\end{array} & \\ \text { Basal + nitrate } & \text { value } & \text { Macromorphology } \\ & \text { None } & 8 \cdot 1 & \text { Dendroid } \\ \text { Basal + glucose + nitrate } & 0 \cdot 5 & 7 \cdot 4 & \text { Parenchymatous } \\ & 1 \cdot 0 & 7 \cdot 5 & \text { Slight growth } \\ \text { Basal + glucose } & 0 \cdot 5 & 7 \cdot 4 & \text { Lanose } \\ & 1 \cdot 0 & 7 \cdot 4 & \text { Lanose } \\ & \text { None } & \mathbf{6 \cdot 0} & \text { Lanose } \\ & 0 \cdot 5 & 7 \cdot 4 & \text { Lanose } \\ & 1 \cdot 0 & \mathbf{7 \cdot 4} & \text { Lanose }\end{array}$

The origin of short motile trichomes at the base of dendroid structures is not clear; it seems possible that they may represent the alternative development of a nonheterocystous generation from cells of the aseriate stage (Lazaroff \& Vishniac, 1962).

The dendroid thallus is phototropic. The tips of the macrostructures bend toward a unidirectional light source as shown in Pl. 5, fig. 18. 


\section{Colonial morphogenesis of a blue-green alga}

The lanose thallus exhibits a microscopic structure entirely different from the oriented cell and filament types of the dendroid thallus (Fig. 2). In the lanose thallus long filaments with intercalary heterocysts predominate and there is no orientation of filaments. Although hormogonia are not formed, there is some breaking of filaments and the development of the aseriate phase from fragments. However, most of the growth in thalli exhibiting the lanose macrostructure is by elongation (cell division) of heterocystous filaments.

It was initially thought that the effect of glucose on development was due to the more rapid decrease in $\mathrm{pH}$ value which occurs in such cultures (Table 1). It may be noted, however, that buffering the glucose cultures at $\mathrm{pH} \mathbf{7 \cdot 2}$ with tris buffer still resulted in lanose growth (Table 2). Similarly, in media containing nitrate and glucose the $\mathrm{pH}$ value increased during incubation and the lanose morphology occurred. When the nitrate had been consumed the $\mathrm{pH}$ value decreased again.

A decrease in $\mathrm{pH}$ value of blue-green algal cultures has frequently been noted (Allison et al. 1937) and has usually been attributed to a replacement of utilized cations by hydrogen ions and not to the liberation of an acidic compound. It was found in the present work that a volatile acid could be distilled from the filtered supernatant fluids of acidic cultures. It seemed possible that the acid, which is produced in larger quantities in media containing glucose, might cause the lanose development regardless of the actual $\mathrm{pH}$ value. The addition of neutralized filtersterilized supernatant media from old glucose cultures to fresh cultures produced morphological changes which supported this speculation. Particularly noticeable were the same modifications in the morphology of the heterocysts that were evident in older cultures containing glucose. Also, the germination of heterocysts which had been noted only rarely in past studies were found with greater frequency in the above experiment. A photomicrograph of this phenomenon is shown in Pl. 5, fig. 19. A particularly striking effect was noted when lanose material was transferred to culture vessels containing fresh basal medium + sucrose or glucose. Extremely long hormogonia were formed. After this treatment, the heterocysts often appeared to divide or be otherwise modified before to hormogone liberation (Pl. 5, fig. 20).

By blending inocula and washing with sterile media it was possible to influence the course of colonial development in shaken cultures of Nostoc muscorum A. Normally a young blended inoculum will produce suspended star-shaped colonies in agitated cultures. The points of these star-shaped formations correspond to the tufts in the dendroid morphology seen in static culture. When the blended suspension is centrifuged, the pellets form more slowly and are devoid of the dendroid protuberances during their initial period of growth (Pl. 6, figs. 21, 22). When the blended suspension is recombined with its washings before inoculation a more nearly normal pattern of development occurs. When shaken cultures containing glucose are inoculated with blended suspensions, the star-shaped pellets form initially, and then become lanose as growth progresses. These observations suggest that substances of developmental significance are liberated into the culture medium by the growing organism.

\section{DISCUSSION}

The simplicity of thallus organization displayed by macrostructures of Nostoc muscorum A offers a particular advantage to studies of morphogenesis. The effect of factors which influenced the development of specific cells or filaments could be 
related to the organization of thallus form and structure. It was possible to grow N. muscorum A as an ordered thallus (dendroid form) or as one lacking in suprafilamentous organization (lanose form). At the developmental level, the ability to differentiate motile hormogonia determines whether a dendroid or a lanose thallus is formed. This, in turn, reflects a biochemical control which altered when $N$. muscorum $\mathbf{A}$ is grown in the presence of glucose. The primary metabolic difference between sucrose and glucose cultures appears to be one of degree, since old sucrose cultures may eventually become lanose and young glucose cultures initially form hormogonia for a limited period. Another way of describing this phenomenon would be to say that glucose cultures lose the ability to form motile hormogonia rapidly, while sucrose cultures lose this ability slowly. The more rapid loss of ability to form motile hormogonia in glucose cultures appears to parallel the more rapid decrease in $\mathrm{pH}$ value encountered in those cultures as compared with sucrose cultures. However, since buffering at neutrality still results in lanose cultures when glucose is carbon source, the lanose morphology cannot be attributed to the effects of increased $\mathrm{pH}$ value. In cultures containing glucose + sucrose development is always lanose, a fact which lends support to the idea that the metabolism of glucose, in some manner, inhibits the normal developmental potential of $N$. muscorum A. The presence of sucrose is not responsible for the dendroid morphology since that type of macrostructure is normally found in photo-autotrophic cultures as well. The lanose mode of development is found not only as the result of growth in the presence of certain sugars. A culture designated $N$. muscorum w was obtained from the Department of Botany of the University of Wisconsin, which seemed very similar to $N$. muscorum A. However, this strain w did not produce motile hormogonia under any condition investigated, and displayed the lanose type of growth in all media.

Previous reports have described developmental responses of the Nostocaceae to photo-stimuli (Harder, 1917, 1920; Lazaroff \& Vishniac, 1961; Lazaroff \& Schiff, 1962). The developmental cycle of Nostoc muscorum a requires light of a particular spectral quality for its expression (developmental photo-induction). Also, a considerable degree of plasticity may occur within the developmental cycle, in response to external factors. Therefore the form and structure of thalli of $N$. muscorum a are dependent upon the same external stimuli which are capable of evoking the differentiation of particular cell-filament types or altering the periodicity of their formation. The orientation of particular cell-filament types in the developing thallus is a consequence of the sequential formation of the various differentiated stages. Prolongation of any phase of the developmental sequence will give rise to changes in thallus form. An extreme example is found in the lanose thallus wherein hormogone formation is inhibited and the prolonged growth of heterocystous filaments leads to breakdown of thallus organization.

In nature the spectral quality of incident light may be the external stimulus which controls the organization of the nostocacean thallus. It has been shown that red light is required for induction of filamentous development from the aseriate stage and that green light counteracts this effect (Lazaroff \& Schiff, 1962). The inductive potency of white light for development of Nostoc muscorum a depends upon the balance between its red and green components. Daily and seasonal shifts in the spectral transmission of sunlight might be expected to exert a periodic influence upon the morphology of the nostacacean thallus. 
It seems reasonable to speculate that the more complex ordered thalli displayed in nature by other groups of cyanophyta may also depend upon a sequence of cellfilament development initiated by a photo-stimulus. Inasmuch as the same basic morphological types of cells and filaments occur throughout the hormogonales, it is expected that their developmental patterns will also display elements of similarity. Perhaps the ultimate unity in cyanophycean development is to be sought at the molecular level in the phycobilin chromoproteins which may function as photoreceptors for developmental induction.

\section{REFERENCES}

Allison, F. E., Hoover, S. R. \& Morris, H. J. (1937). Physiological studies with Nostoc muscorum. Botan. Gaz. 98, 433.

Bornet, E. \& Thuret, G. (1880). Notes algologiques. Paris: G. Masson.

Cannabaeus, L. (1929). Über die Heterocysten und Gasvacuolen der Blaualgen und ihre Beziehungen zueinander. Pflanzenforschung, 13. Jena: Springer.

Fremy, P. (1930). Les Myxophycées de L'Afrique Equatorial Française. Paris: Edition des Archives de Botanique.

Fritsch, F. E. (1945). The Structure and Reproduction of the Algae, 2. Cambridge: University Press.

GeITLER, L. (1932). Cyanophyceae. In Rabenhorst, Kryptogamenflora, 14. Leipzig: Akademische Verlagsgesellchaft.

HARder, R. (1917). Über die Beziehung des Lichts zur Keimung von Cyanophyceensporen. Jb. wiss. Bot. 58, 237.

Harder, R. (1920). Utber die Reaktion freibeweglicher pflanzlicher Organismen auf plötzliche Änderungen der Lichtintensität. Z. Bot. 12, 353.

LAZAROFF, N. (1955). The demonstration of a developmental cycle in the growth of a bluegreen alga. Bact. Proc. p. 59.

Lazaroff, N. (1960). The Effect of Light on the Developmental Cycle of Nostoc muscorum. Dissertation. Yale University.

Lazaroff, N. \& Vishniac, W. (1961). The effect of light on the developmental cycle of Nostoc muscorum, a filamentous blue-green alga. J. gen. Microbiol. 25, 365.

Lazaroff, N. \& Vishniac, W. (1962). The participation of filament anastomosis in the developmental cycle of Nostoc muscorum, a blue-green alga. J. gen. Microbiol. 28, 203.

LazarofF, N. \& Schiff, J. (1962). The action spectrum for developmental photo-induction of the blue-green alga Nostoc muscorum A. Science, 137, 603.

Manten, A. (1948). Phototaxis, phototropism and photosynthesis in purple bacteria and bluegreen algae. Dissertation. University of Utrecht.

Zastrow, E. M. von (1953). Über die Organisation der Cyanophyceenzelle. Arch. Mikrobiol. 19, 174.

\section{EXPLANATION OF PLATES}

\section{Plate 1}

Fig. 1. An ordered nostocacean colony. A portion of planktonic colony of Anabaena circinalis collected from Lake Mendota, Wisconsin. Akinetes and heterocysts occupy the inner ends of trichomes, which converge to form the centre of the colony. Vegetative cells occupy the curved external portions of the trichomes. $\times \mathbf{7 5 0}$.

Fig. 2. Hormogonia developing into aseriate stage (bottom). New filament formation from the aseriate stage (top). Growth on the surface of agar medium incubated at a continuous light intensity of $200 \mathrm{ft}$. candles. $\times 1500$.

Fig. 3. Aseriate stage cells, after 5 weeks growth in complete darkness in liquid medium containing $1 \%$ glucose. $\times 1000$.

Fig. 4. Heterocystous filaments mounted in India ink. The morphology of the sheath reflects the origin of these filaments from the aseriate stage. $\times 270$. 
Plate 2

Fig. 5. Sporogenous filaments (in liquid mount stained with methylene blue). Each two celled fragment has a common sheath which differs from the sheath of the original parent filament. The two celled structures, which may be interpreted as two celled spore germlings, are capable of motility after emerging from the sheath. $\times 620$.

Fig. 6. The spiral aggregation of gliding hormogonia on the surface of agar medium. $\times 230$.

Fig. 7. The spiral aggregation of motile trichomes in liquid culture. $\times \mathbf{2 4 5}$.

Fig. 8. Spiral aggregates of motile trichomes are oriented within a developing micro-colony imbedded in soft agar. The basal agar plus sucrose was seeded with a blended suspension, then incubated in darkness until aseriate micro-colonies had formed. Continuous exposure to 'cool white' fluorescent illumination (200 $\mathrm{ft}$. candles) for four days produced colonies of the type shown. The colonies correspond to the dendroid morphology exhibited by liquid cultures containing sucrose. The initiation of dichotomous growth is seen to result from the pattern of motile filament migration. It may also be noted that the hormogonia are capable of burrowing through the soft agar. $\times 210$.

\section{Plate 3}

Fig. 9. New filament formation from spiral aggregates of hormogonia on the surface of agar medium. In the lower right can be seen a large revolving aggregate composed of many motile trichomes. In the upper left is seen the formation of aseriate cells from a spiral aggregate as well as the later stage of new filament formation. During the formation of new filaments anastomosis takes place between aseriate cells originating from the same hormogone and between cells from different hormogonia. In the upper right section is seen the development of new filaments from a spiral aggregate which had consisted of a few hormogonia. Heterocysts have differentiated and new hormogonia are about to be liberated. The central portion of the photograph shows a stream of gliding hormogonia. At intervals, trichomes from such formations separate from the swarm and form the revolving spiral aggregates. $\times 300$.

Fig. 10. The long heterocystous filaments which are formed in mature cultures containing glucose. Heterocysts are originally bean shaped but may become elongated as growth proceeds. $\times 1000$.

Fig. 11. Long heterocystous filaments from cultures containing glucose, showing the dark refractile inclusions within many of the cells. $\times 1300$.

Fig. 12. At the left and right is shown the parenchymatous macromorphology displayed in illuminated tube cultures, containing sucrose, prior to development of the dendroid form. In the tube at the right, dendroid structures are just beginning to form at the upper margin of growth. In the centre is shown a dendroid culture grown in liquid medium containing glucose under continuous illumination. $\times \mathbf{3 \cdot 2}$.

\section{Plate 4}

Fig. 13. At the left is a young parenchymatous culture which has been swirled to separate the thin layers of adherent growth from the walls of the tube. At the right is a lanose culture containing glucose. It is composed of loosely packed long heterocystous filaments. $\times \mathbf{3 \cdot 6}$.

Fig. 14. Erect macrostructures produced by exposing dark-grown cultures, containing sucrose to light for several hours, then returning to complete darkness. The protuberances have a marked symmetrical structure which is rapidly altered by subsequent light exposure. Note the radial 'crown' of hormogonia at the tips of the protuberances. $\times 7$.

Fig. 15. Hormogonia at the tip of a dendroid protuberance. Colonies grown in shake culture, photoautotrophically. $\times 150$.

Fig. 16. Aggregation of hormogonia at the tip of a dendroid protuberance. $\times 170$.

\section{Plate 5}

Fig. 17. Development of 'gemmae' in a mature colony partially embedded in soft agar. The colony had formed hormogonia which swarmed leaving behind masses of deposited heterocysts. Some of the motile trichomes aggregated at the periphery of the original colony producing a second cycle of development. In the centre of the colony, smaller aggregates 'rounded up' and contracted to form 'gemmae' (arrows). These multicellular spore-like structures are also found within dendroid thalli produced in liquid culture. $\times \mathbf{2 5 0}$. 

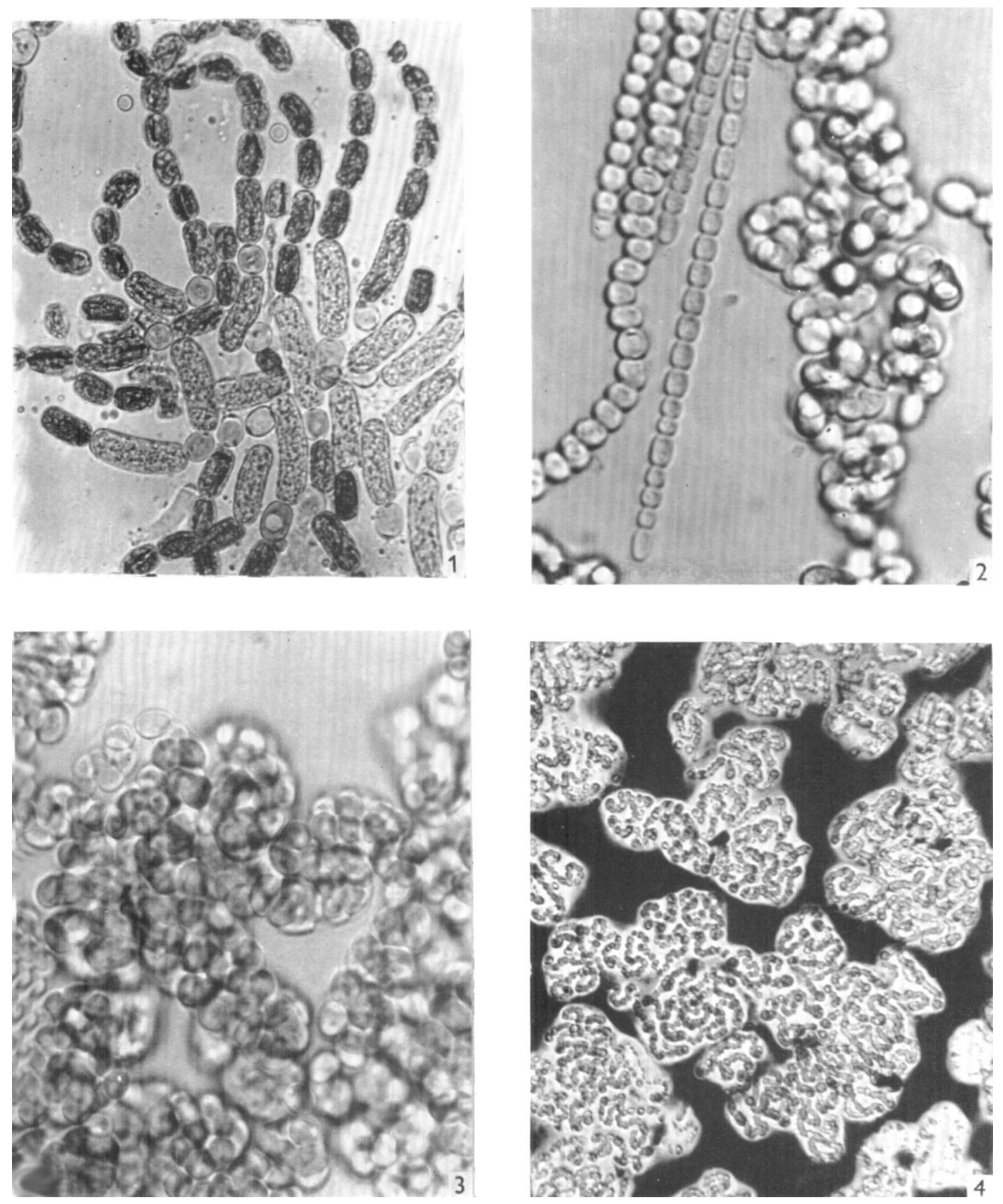

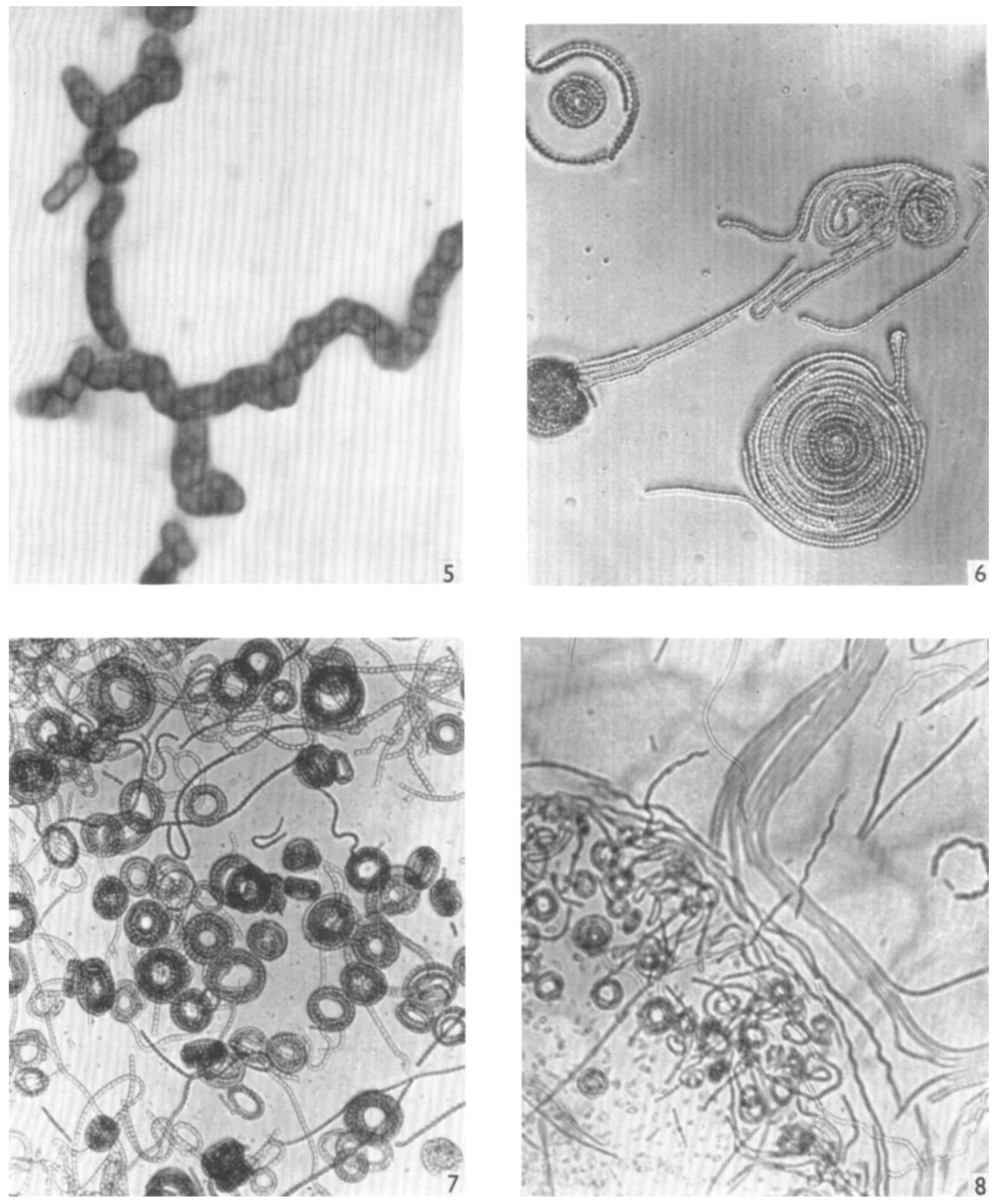

N. LAZAROFF AND W. VISHNIAC 

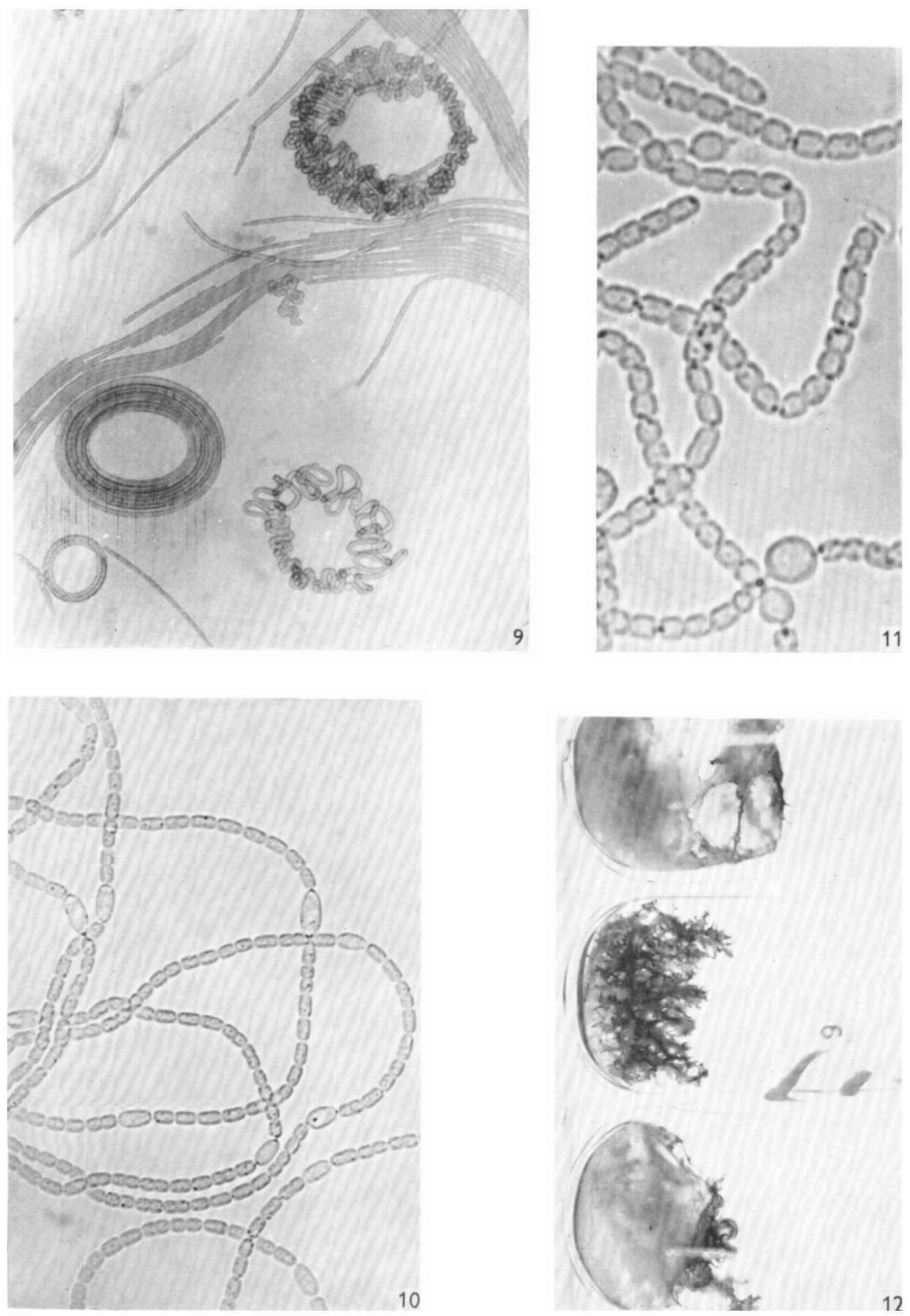

N. LAZAROFF AND W. VISHNIAC 

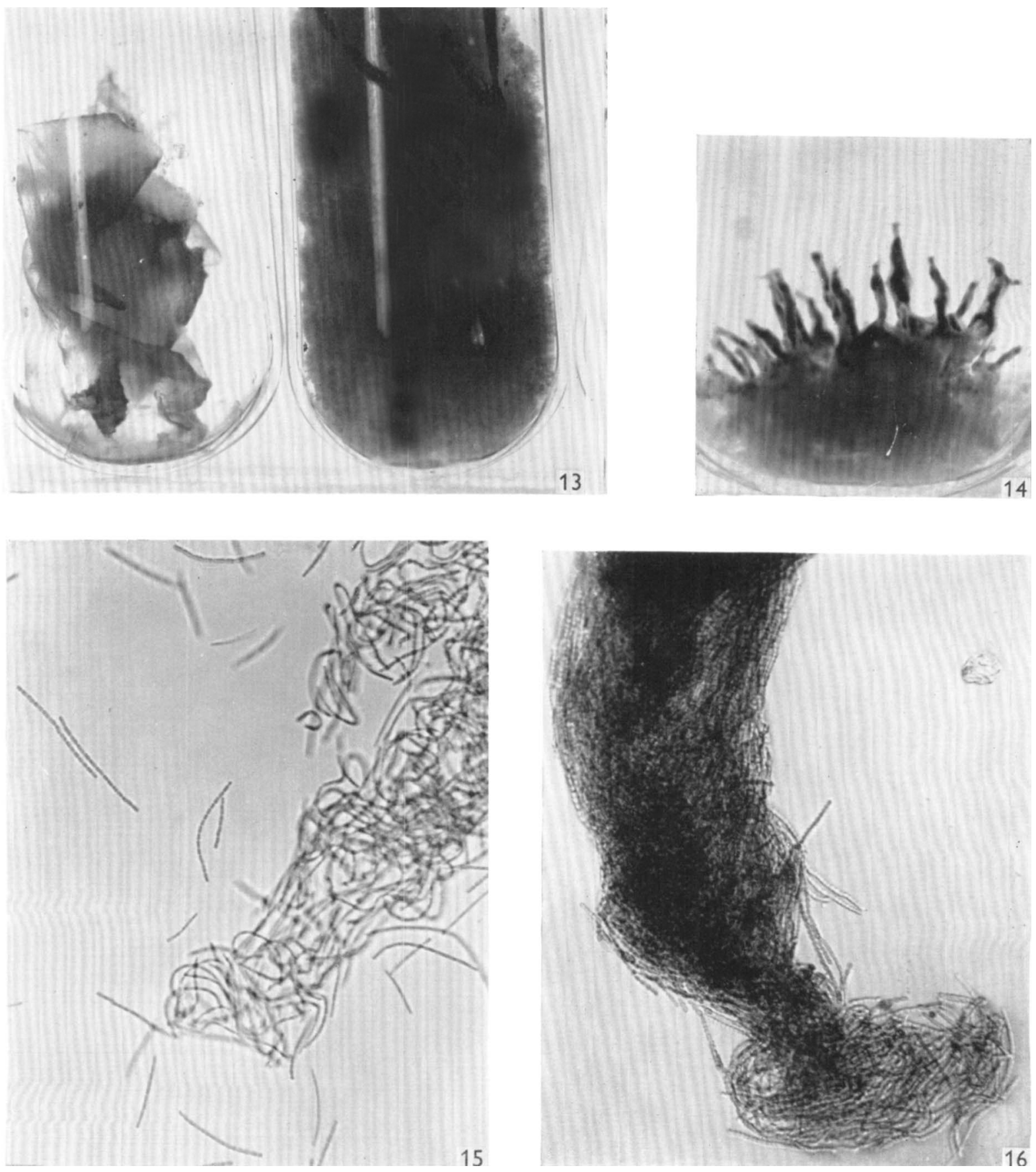

N. LAZAROFF AND W. VISHNIAC 

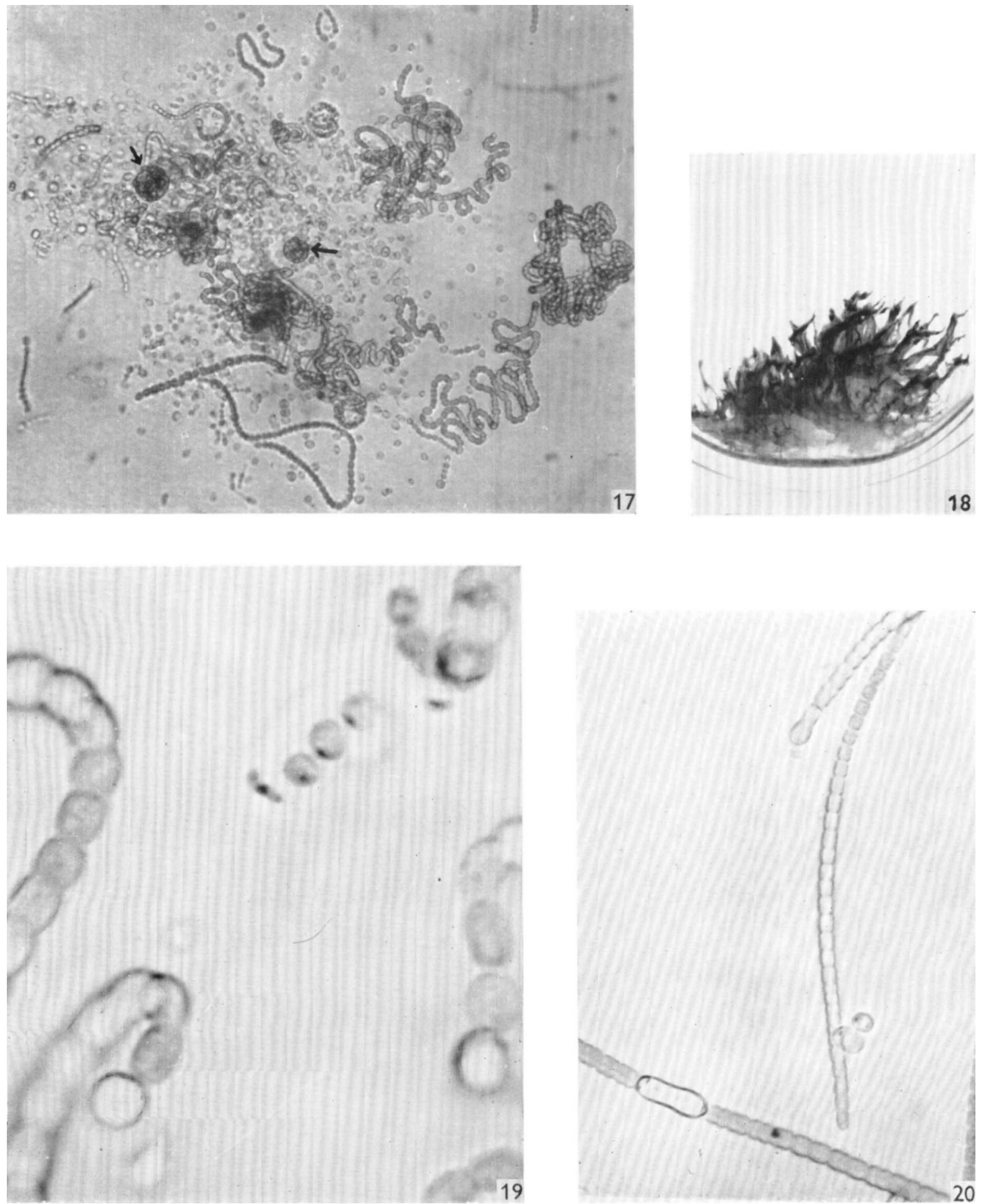

N. IAAZAROFF AND W. VISHNIAC 
Journal of General Microbiology, Vol. 35, No. 3

Plate 6
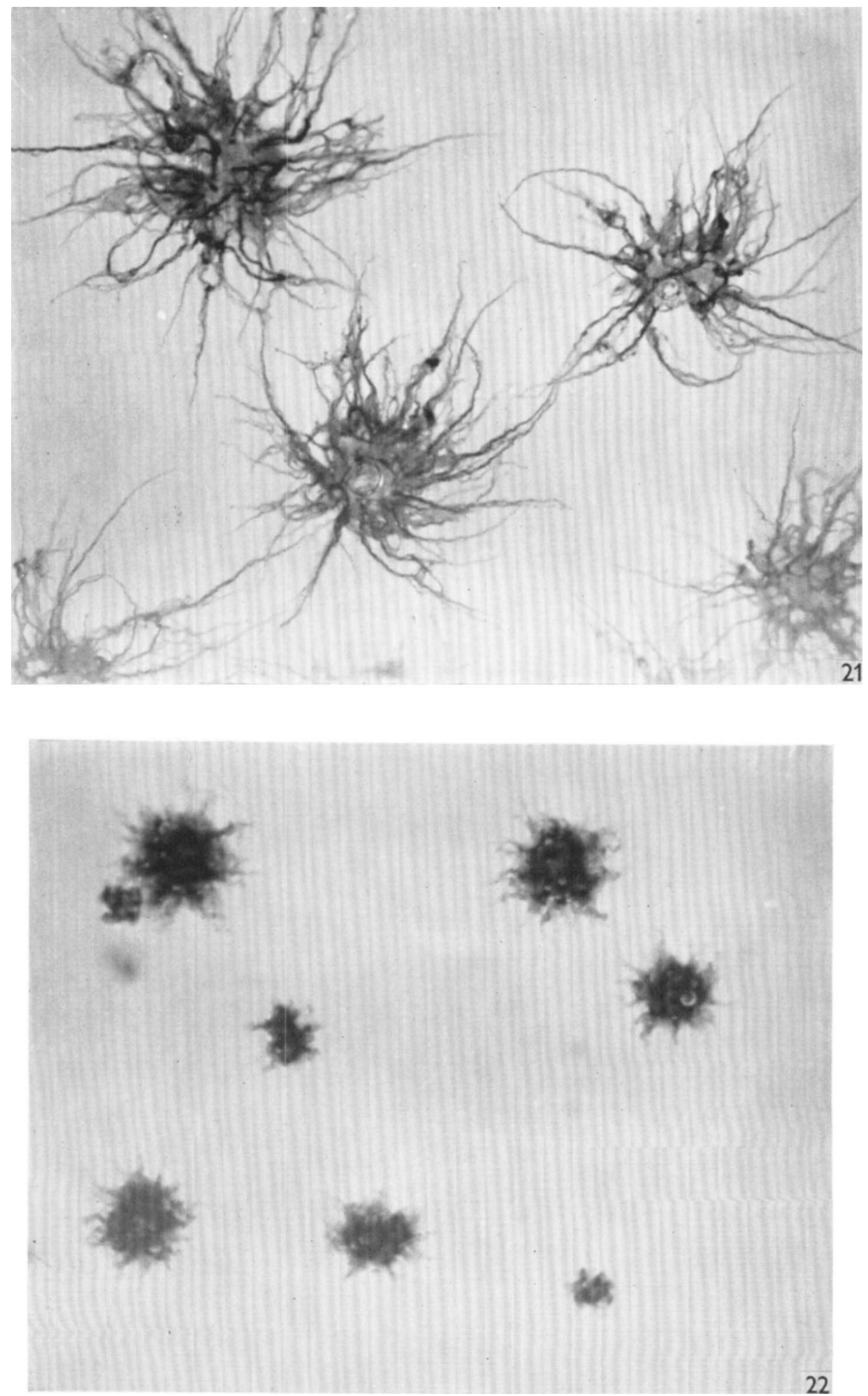
Fig. 18. A dendroid culture which has been illuminated from one side. A positive phototropism is displayed. $\times 7 \cdot 4$.

Fig. 19. The 'germination' of a heterocyst. This phenomenon was observed in old illuminated cultures containing sugars. $\times \mathbf{2 6 0 0}$.

Fig. 20. Lanose filaments which had been transferred to media containing sucrose. Extremely long hormogonia form. Heterocysts divide or are considerably modified. $\times 1000$.

\section{Plate 6}

Fig. 21. Unwashed blended inocula, prepared from young cultures grown in basal media, produce dendroid macro-colonies in shake culture. Hormogonia produced within 4 days. $\times 4$. Fig. 22. Washed, blended inocula, prepared from young cultures grown in basal media, do not produce dendroid colonies at the inception of growth in shake culture. The colonies produced in shake cultures are compact masses which may fail to differentiate motile trichomes for 10 or more days. In this figure, colonies produced from washed inocula have just begun to form the dendroid structure although inoculated at the same time as the preparation shown in Fig. 21. $\times 4$. 